\title{
ПОНИМАНИЕ КОНФЛИКТА \\ С ТОЧКИ ЗРЕНИЯ ПСИХОЛОГИИ И ПРАВА
}

\author{
Т. Н. Сафронова \\ Воронежский государственный университет \\ Поступила в редакцию 15 декабря 2020 г.
}

\begin{abstract}
Аннотация: анализируется различие подходов к пониманию конфбликта в психологии и юриспрудениии. Автор рассматривает признаки конфбликта, выделяелье в психологии, с точки зрения права приленяет классифбикаиию конфбликтов на реалистические и нереалистические к правовыл ситуациял. Выявляются причины, по которыли существование конфбликтов с неизбежностью присуще и частному, и публичному праву.
\end{abstract}

Ключевые слова: противоречие, конфбликт, спор о праве, стороны правового конфбикта, реалистический и нереалистический конфбликты.

\begin{abstract}
: the paper analyzes the difference in approaches to understanding conflict in psychology and jurisprudence. The author considers the signs of conflict distinguished in psychology, from the point of view of law, applies the classification of conflicts into realistic and unrealistic to legal situations. The work also identifies the reasons why the existence of conflicts with inevitability is inherent in both private and public law.

Key words: contradiction, conflict, legal dispute, parties to legal conflict, realistic and unrealistic conflicts.
\end{abstract}

Категория «конфликт» и типология конфликтов являются предметом исследования многих наук, причем не только гуманитарных. В одном из междисциплинарных обзоров работ по исследованию конфоликтов выделяются 11 областей научного знания, изучающих это явление: психоло으 гия, социология, политология, история, фрилософия, искусствоведение, педагогика, правоведение, социобиология, математика, военные науки ${ }^{1}$. Казалось бы, что юриспруденщия в большей мере из всех перечисленных наук связана с конфликтными ситуациями, однако в этом списке, располагающем области знания по мере убывания количества исследований,

334 занимает 8-е место. При определении правового конфликта юристы в значительной мере пользуются наработками социальной психологии и социологии, а количество литературы, посвященной правовой конфликтологии, не так уж велико.

Многочисленные определения конфликта, сформулированные как в психологических, так и в социологических исследованиях, как правило, используют терминологию «противостояние, противоречие, противодействие, противоборство». Можно привести следующие дефиниции: «ситуация, когда стороны взаимодействия преследуют какие-то свои цели,

${ }^{1}$ См.: Гришина Н. В. Психология конфрликта. 3-е изд. СПб., 2016. С. 13.

(C) Сафронова Т. Н., 2021 
которые противоречат или взаимно исключают друг друга»²; «такое отношение между субъектами социального взаимодействия, которое характеризуется их противоборством на основе противоположно направленных мотивов (потребностей, интересов, целей, идеалов, убеждений) или суждений (мнений, взглядов, оценок)»³.

Взгляды психологов и социологов на конфликт далеко не всегда совпадают. Скажем, в психологии принято выделять внутриличностные конфрликты, связанные со столкновением мотивов и побуждений самого человека (например, между "хочу» и «должно»; "хочу» и "хочу»; "хочу» и «не могу» и т. д.). Пока в поле внутренней конфронтации не появился другой субъект, а внутреннее противоречие не вылилось в отношение с другим лицом, такой конфликт не выходит за рамки изучения психологических наук и скорее интересен не для социальной психологии, а исключительно для психологии личности.

Убедительно и достаточно емко признаки конфрликта называются в работах серьезного специалиста в области его изучения Н. В. Гришиной. В частности, ею выделяется биполярность данного явления, что означает и взаимосвязанность, и противоположность интересов. Сама по себе противоположность интересов не влечет с неизбежностью конфрликт, поскольку для его возникновения необходимы борьба, активные действия, направленные на преодоление противоречия. И для такой борьбы, безусловно, требуется наличие субъектов как носителей конфрликта ${ }^{4}$. Г. Хесль отмечает, что конфликт существует, если одна сторона придерживается определенных тенденций в поведении, которые не могут быть согласованы с аналогичными тенденциями другой стороны, или, по крайней мере, их согласование кажется невозможным. При этом поведение понимается им в широком психологическом смысле, поэтому предметом разногласий могут являться и интересы, и мнения, и ценности, и чувства симпатии ${ }^{5}$.

Попытаемся перенести выделенные психологами признаки конфрликта на правовую почву, опираясь в первую очередь на частноправовые отношения. Противоположность интересов может быть связана с заинтересованностью сторон правового конфликта в том или ином благе, материальном или идеальном, при его ограниченности, неравномерном распределении или неравном доступе к нему; в желании сохранить то или иное благо, не передавая или не возвращая его другой стороне; в претензии одной стороны на то, что она считает своей при формальной закрепленности этого за другим лицом. Иллюстрируя институциональную ценность права собственности, итальянский цивилист У. Маттеи

${ }^{2}$ Столяренко Л. Д., Сальцин С. Психология общения : учебник. Ростов н/Д., 2014. С. 271.

${ }^{3}$ Елельянов С. М. Практикум по конфликтологии. СПб., 2005. С. 24.

${ }^{4}$ См.: Гришина Н. В. Указ. соч. С. $18-22$.

${ }^{5}$ См.: Хесль Г. Посредничество в разрешении конфликтов. Теория и технология. СПб., 2004. С. 11-12. 


\section{Вестник ВГУ. Серия: Право}

отмечает, что регламентация отношений собственности, независимо от того, какой инструментарий использует для этого правовая система, направлена на решение или предупреждение конфликта по поводу распределения ограниченных ресурсов ${ }^{6}$. Если обратиться к обязательственным отношениям, то должник, не возвращающий долг, демонстрирует тем самым желание сохранить за собой ту сумму, которую по условиям договора необходимо вернуть другой стороне.

Возникает вопрос: является ли активное действие признаком правового конфликта? Представляется, что да. Причем под действием мы должны понимать различные поведенческие реакции, включая вербальные. Словесная реакция может рассматриваться как поведение, нарушающее права другого лица. А вот мысли, симпатии или антипатии, чувства, не получившие объективного выражения, с точки зрения права в качестве ситуации, создающей правовой конфликт, выступать не могут, хотя могут являться источником его созревания, способным привести в дальнейшем к конфликтной ситуации. Один из основоположников теории социального конфликта Л. Козер отмечает, что «враждебное отношение представляет собой предрасположенность к конфрликтному поведению; конфрликт же, напротив, всегда трансакция» ${ }^{7}$ В В современных исследованиях приводится следующая формула социального конфликта, применимая и к его правовой вариации: «конфрликт = конфрликтная ситуация + субъекты + инцидент». Конфликтная ситуация в такой формуле является предпосылкой зарождения конфликта, способной обратиться в правовой спор, инцидент же возникает в том случае, если одна из сторон предпринимает активные действия против другой стороны ${ }^{8}$.

В юридической литературе высказываются различные взгляды по поводу соотношения юридического конфликта и спора о праве. В основ-

- ном исследователи сходятся во мнении о тесной связи этих категорий.

일 Сама категория «спор о праве» не имеет законодательной расшифровки и раскрывается доктринальным образом. Так, известный процессуалист И. М. Зайцев, рассматривая спор как юридическую форму конфоликта, отмечал, что такой конфликт должен иметь юридическое содержание (определенным образом отражаться на правах и обязанностях его участ-

336 ников), а спорящие должны занимать в нем такое положение, которое препятствовало бы каждому из них своей волей ликвидировать конфрликт ${ }^{9}$. В научных публикациях по теории права и гражданскому процессу спор рассматривается как юридическое содержание конфликта; как определенная стадия развития конфликта; внешнее и формальное проявление

${ }^{6}$ См.: Маттеи У., Суханов E. А. Основные положения права собственности. M., 1999. C. 23-25.

${ }^{7}$ Козер Л. Функции социального конфрликта. М., 2000. С. 57.

${ }^{8}$ См.: Старыгина П. С. Юридический конфликт : понятие, причины, особенности, типология // Марийский юридический вестник. 2018. № 2 (25). С. 16.

${ }^{9}$ См.: Зайцев И. М. Хозяйственный спор и арбитражный процесс : вопросы теории. Саратов, 1982. С. 22. 
юридического конфоликта ${ }^{10}$. В данной статье мы не ставим задачу детального анализа сложнейшей конструкции «спор о праве». На наш взгляд, основой спора о праве является нарушение субъективного гражданского права одной стороны другой стороной материального правоотношения, в котором и возникает данный юридический конфрликт. Облечение этого конфрликта в ту или иную процедурную форму зависит от избранной его сторонами стратегии разрешения спорной ситуации.

В выдающейся по своей силе и вдохновению работе «Борьба за право» немецкий юрист Рудольф фрон Иеринг, рассуждая о защите субъективного права, пишет, что «международное восстановление нарушенного права в фрорме войны...; насильственное осуществление частного права в виде... средневекового кулачного права и права самозащиты; самозащита в форме необходимой обороны; и наконец, упорядоченный вид защиты права в форме гражданского процесса - всё это виды и сцены из одной и той же борьбы за право, при всем различии спорных объектов и жертв» ${ }^{11}$. Безусловно, спор, облеченный в процессуальную форму, представляет собой законный и цивилизованный способ разрешения многих правовых конфрликтов.

Нарушение права обычно представляет собой активное поведение, хотя в более редких ситуациях и бездействие может квалифицироваться в качестве правонарушения. Но в любом случае правовой спор возникает тогда, когда другая сторона отреагировала на правонарушение, например, направив претензию, обратившись в суд с иском. Скажем, позиция кредитора, не требующего возврата просроченного долга, не означает его прощение, но и не порождает спор, следовательно, и правовой конфрликт. При этом предпосылка конфликта в виде сохраняющегося дисбаланса положения сторон продолжает иметь место. Недовольство должника, надлежащим образом исполняющего обязательство, его агрессивное поведение, не породит правовой конфликт, если только должник не посягнул на иное благо контрагента, например честь и достоинство. Внутриличностный конфликт исправного должника между «должно платить, но не хочу» может быть предметом исследования лишь для психолога.

Интересно порассуждать применительно к правовой материи и о субъектах конфликта, признаваемых обязательным его элементом психологами и социологами. Понимание субъекта может принципиально различаться в праве и в других областях общественных наук. Оставляем за скобками права внутриличностный конфликт, неподвластный правовой материи, не имеющий как минимум двух субъектов противостояния. К примеру, в социологии и психологии среди социальных конфликтов принято выделять межличностные конфрликты, конфликты между лич-

${ }^{10}$ См.: Губайдуллина Э. Х. Спор о праве - фрорма юридического конфликта : теоретический аспект // Вектор науки Тольяттинского гос. ун-та. 2013. № 1 (23). C. 171-173.

${ }^{11}$ См.: Иеринг Р. фбон. Борьба за право // Избранные труды. Самара, 2003. C. 466-467. 
ностью и группой, межгрупповые конфликты, дальнейшее деление которых зависит от размера группы (между малыми, средними и большими группами), а также межгосударственные конфрликты ${ }^{12}$.

Однако не всякая группа с точки зрения права может рассматриваться в качестве стороны спора. Например, в ситуации корпоративного конфрликта между участниками юридического лица, блокирующими избрание генерального директора и тем самым осложняющими деятельность юридического лица, используя язык конфликтологии, можно вести речь о межличностном конфликте. Но спор участника юридического лица с акционерным обществом по поводу выплаты дивидендов не может рассматриваться как конфрликт личности и группы, поскольку в случае с юридическим лицом мы имеем не группу, а единичного, хотя и фриктивного, субъекта права. Такой спор фризического и юридического лица не вписывается в социологическую классификацию конфликтов. Спор двух юридических лиц по поводу ненадлежащего исполнения обязательств нельзя квалифицировать в качестве конфликта между малыми группами, поскольку с точки зрения конструкции «субъект права» юридические лица не могут рассматривать как группы. При этом и к межличностным конфликтам такой спор отнести невозможно. Исследователи, занимающиеся правовыми конфликтами, отмечают, что в юридическом конфрликте можно выделять в качестве субъектов фризических и юридических лиц, причем конфрликт последних обязательно приобретает юридический характер, потому что между этими субъектами всегда складываются правовые отношения, и разрешить их можно лишь юридическим путем ${ }^{13}$. Изложенное выше приводит нас к выводу о том, что правовые классификации конфликтов по причине юридической формализации субъектов отношений требуют подходов, в определенной мере отличных от социоло- гических.

인 Большие группы, упоминаемые в социологической и психологической литературе в качестве участников конфликта, тоже далеко не всегда находят формализованное закрепление в праве в качестве носителей правоспособности. Например, народ или нацию сложно рассматривать в качестве участника конкретного правового отношения. По крайней мере,

338 в частном праве эта идея прослеживается с наибольшей очевидностью. Когда же речь идет о нарушении государственной собственности, в качестве потерпевшей стороны в конфрликте точно не может выступать народ, проживающий на территории государства, или какая-то часть населения. Юридическая техника формулирует здесь конструкцию единичного субъекта права - государства, что снимает необходимость говорить о множестве субъектов права собственности, о «коллективной собственности», которая с точки зрения юридической логики выглядит нонсенсом.

${ }^{12}$ См.: Аниупов А., Баклановский С. Конфликтология : учеб. пособие. 3-е изд. СПб., 2013. С. 96-97.

${ }^{13}$ См.: Юридическая конфликтология / отв. ред. В. Н. Кудрявцев. М., 1995. C. $18-19$. 
Мы не беремся анализировать субъектный состав публично-правовых отношений, но представляется, что и здесь указание в правовых нормах больших социальных общностей, таких как «народ», «нация», нередко преследует идеологические цели, в большей мере исходит из морально-политических идей, чем придает такой общности статус субъекта права. Невозможно представить правоотношение, в котором называемый Конституцией РФ народ имел бы конкретные права и обязанности как носитель правосубъектности, а следовательно, правового статуса. Например, применительно к избирательным правоотношениям, в рамках которых народ формирует государственную власть, в первую очередь идет речь о правовом положении, правах, порядке участия в выборах каждого отдельного избирателя. Последний и является участником правоотношений, а правовые конфликты возникают между определенными субъектами избирательного права, включая граждан-избирателей, избирательные комиссии, различных должностных лиц.

Не затрагивая всё многообразие классификационных критериев социальных конфликтов, остановимся на любопытнейшей их классификации (безусловно, влияющей и на стратегию разрешения конфликта), предложенной Л. Козером. Автор выделяет реалистический и нереалистический конфликты, в основе которых, на его взгляд, лежит различение конфрликта как средства и конфликта как цели. Первые, будучи средствами достижения определенного результата, возникают из-за неудовлетворения требований в рамках отношений субъектов, в которых они не получают ожидаемых от отношения выгод. Источники таких конфликтов могут заключаться в самой социальной системе, где распределение статусов, власти, ресурсов может оставаться предметом соперничества. В нереалистическом конфликте конфликтующим важно не достижение результата, а выражение своих агрессивных эмоций. Удовлетворение черпается здесь в самом акте агрессии, которая может направляться даже на заранее неопределенный объект ${ }^{14}$. Данное деление непосредственно влияет на способы выхода из конфрликта.

В реалистическом конфликте стороны стремятся к определенной цели, поэтому он способен исчерпать себя при ее достижении. В данном случае стороны имеют возможность выбирать различные способы достижения цели, оценивая инструментальную адекватность тех или иных средств. Например, при неисполнении обязательства должником кредитор будет оценивать свои перспективы обращения в суд с точки зрения соотношения последствий нарушения и издержек на ведение тяжбы. С другой стороны, неисправный должник также взвешивает перспективы возможного взыскания с него долга и штрафрных санкций как альтернативу соглашений с кредитором, направленных на рассрочку исполнения, частичное прощение кредитором долга, реструктуризацию долга. В уже упоминавшейся работе Рудольф фон Иеринг обосновывает идею о том, что борьба за право есть долг управомоченного лица по отношению и к

${ }^{14}$ См.: Козер Л. Указ. соч. С. 71-79. 


\section{Вестник ВГУ. Серия: Право}

самому себе, и к чувству права, которое должно быть присуще каждому его носителю, и по отношению к обществу в целом, ведь «в своем праве управомоченный вместе с тем защищает закон, а в законе - необходимый порядок общественной жизни» ${ }^{15}$. Нельзя сказать, что в современной действительности применительно к частному праву этот тезис перестал быть полностью актуальным, но его абсолютизация в современных условиях выглядит несколько наивной. За субъектом, право которого нарушено, должна признаваться свобода в оценке значимости нарушенных интересов и целесообразности их принудительного восстановления через обращение к имеющимся рычагам разрешения правового конфликта.

Для разрешения реалистических конфликтов право способно предложить социально одобряемые, приемлемые для стабилизации общественных отношений рычаги и стратегии. Возможность разрешения спора в исковом порядке - одна из таких стратегий, в которой спор находит свое процессуальное выражение. В качестве поведенческих альтернатив может выступать стратегия переговоров, привлечение медиатора и т. д. В материальном праве закреплены институты прощения долга, отступного, изменения обязательства и другие инструменты, предоставляющие сторонам арсенал возможностей для исчерпания конфликта и нахождения компромисса. Реалистический спор, конечно, тоже может иметь эмоциональную окраску, быть связан с выражением сторонами антипатий. Но неисполнение обязательства или нарушение права собственности, имея в своей основе ограниченность ресурсов, по своей сущности связаны не с антипатиями, а с имущественными интересами сторон.

Иное дело - нереалистический конфрликт, в котором девиант через агрессивное поведение находит пути освобождения от психологического напряжения, а сам объект агрессии может быть в принципе и не столь - значим, став мишенью в силу стечения обстоятельств. Общество на протяжении своей долгой истории создавало «замещающие клапаны», в которые способна выливаться негативная энергия индивида, группы или широких масс. Это и театр, и различные игры, и юмор, доходящий до крайне ядовитых анекдотов, в рамках которых агрессия находит русло, наименее опасное для общества. Иногда речь шла о «козлах отпущения»,

340 т. е. тех лицах или группах, в отношении которых с точки зрения социальной иерархии считалось допустимым выражение агрессивной энергии. Понятно, что в современном демократическом обществе таких «неполноценных» категорий граждан, служащих «громоотводами», быть не должно. Индивидуальные проявления агрессивности, провоцирующие конфликт, - предмет работы психолога, специализирующегося в том или ином направлении психологической практики, а в крайних фрормах - и психиатра.

Правовые нормы вряд ли в состоянии предлагать компромиссные варианты разрешения нереалистических конфликтов, которые основывались бы на идее баланса интересов. В правовом плане здесь скорее

${ }^{15}$ Иеринг Р. фбон. Указ. соч. С. 487. 
должен работать запрет агрессивного поведения, если таковое начинает нарушать права и законные интересы других лиц. Спор соседей о противоречащих друг другу с точки зрения противоположности интересов способах пользования своими участками может быть разрешен при помощи разумных механизмов, включающих обозначение более приоритетного пользования, отсылку к сложившимся обычаям, как это делают некоторые правопорядки, расстановку приоритетов по началу пользования («первый по времени сильнее по праву»). Например, собственник земельного участка, занимаясь свиноводством и получая от этого доход, мешает тем самым собственнику соседнего участка приятно проводить время, наслаждаться природой и приглашать гостей. Однако осуществление права, преследующее исключительную цель навредить другому (шикана) не может поощряться правом ни в каком виде. Скажем, сосед громко слушает тяжелый рок с целью досадить другому соседу, питая к нему личную неприязнь или желая выместить на ком-то свою мизантропию. Статья 10 ГК РФ запрещает такую фрорму поведения, а в качестве негативного последствия использует собирательную формулировку «отказ в защите права». Поиск оптимальных гражданско-правовых вариантов разрешения такого конфликта вместо запрета неправомерного поведения выглядел бы неоправданным.

Право - сфера, в большей мере, чем другие сферы общественной жизни, рассчитанная на конфрликт как возможное противоборство интересов. В этом утверждении не стоит видеть негативный смысл. Вспомним вдохновенные выражения Р. фон Иеринга: «Цель права - мир, путь к нему борьба... Жизнь права есть борьба, борьба народов, государственной власти, сословий, индивидуумов» ${ }^{16}$. В каждой конкретной ситуации мы допускаем, что стороны правового отношения могут обойтись без создания спорной ситуации и мирно исчерпать содержание правоотношения, но ради самой потенциальной опасности столкновения противоположных интересов и необходимо правовое регулирование. В противном случае нормы носили бы не правовое, а техническое значение. Как писал известный юрист прошлого века Е. Б. Пашуканис, «основной предпосылкой правового регулирования является противоположность частных интересов» ${ }^{17}$. По его мнению, это и является причиной развития юридической надстройки, ибо юридический момент начинается там, где имеет место обособленность и противоположность интересов, в то время как единство цели составляет предпосылку лишь технического регулирования. Так, нормы об ответственности железной дороги являются юридическими, поскольку изначально допускают возможные претензии носителей обособленных интересов, а вот правила железнодорожного движения предполагают единую цель и в этом смысле правовыми называться не могут ${ }^{18}$.

${ }^{16}$ Иеринг Р. фбон. Указ. соч. С. 487.

${ }^{17}$ Пашуканис E. Б. Общая теория права и марксизм // Избранные произведения по общей теории права и государства. М., 1980. С. 73.

${ }^{18}$ См.: Там же. С. 73-74. 
Из утверждения, что «форма права с ее аспектом субъективной управомоченности рождается в обществе, состоящем из обособленных носителей частных, эгоистических интересов», Е. Б. Пашуканис делает смелый вывод, что «государственное право может существовать только как отображение частноправовой формы в сфере политической организации или оно вообще перестает быть правом» ${ }^{19}$. Действительно, в глобальном смысле публичное право тоже частно, поскольку не представляет собой монолитное отражение социальной фонкции государства. Необходимость правового регулирования и здесь вызывается возможными противоречиями между отдельными структурами публичной власти, между интересами государства и индивидуальными интересами, иначе нормы превратились бы только в организационные правила, ничего общего с правом, правовой формой не имеющие. Поэтому и публичному праву перманентно присуща возможность возникновения правовых конфликтов, а отсюда и необходимость разработки механизмов, направленных на их разрешение. И только в обществе, где отсутствовали бы противоречия между индивидуальными интересами, интересами социальными и индивидуальными, отпала бы потребность в праве как средстве разрешения этих противоречий. Но такие идеи, как показывает ход истории, являются скорее утопией, чем реальной перспективой общественного развития.

${ }^{19}$ Пашуканис Е. Б. Указ. соч. С. 94-95.

Воронежский государственньй университет

Саббронова Т. Н., кандидат юридических наук, доцент кафбедры гражданского права и процесса

E-mail:stn71@mail.ru
Voronezh State University

Safronova T. N., Candidate of Legal Sciences, Associate Professor of the Civil Law and Process Department

E-mail:stn71@mail.ru 